\title{
COMPARATIVE EFFICACY OF DOMESTIC GARLIC (ALLIUM SATIVUM) AND NEEM (AZADIRACHTA INDICA) AGAINST HAEMONCHUS CONTORTUS IN SMALL RUMINANTS
}

\author{
AZRA, A. ${ }^{1}-$ KALEEMUllah, M. ${ }^{1}-$ KHATTAK, B..$^{2 *}$ - ASMA, N. ${ }^{1}-$ SAFI, A. U. R. ${ }^{2}-$ QAISER,$~{ }^{2}{ }^{2}-$

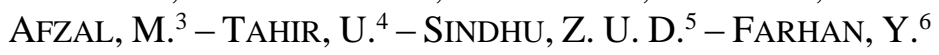 \\ ${ }^{I}$ Depatrment of Zoology, Kohat University of Science and Technology, Kohat, Pakistan \\ ${ }^{2}$ Department of Microbiology, Kohat University of Science and Technology, Kohat, Pakistan \\ ${ }^{3}$ Zhejiang Provincial Key Laboratory of Agricultural Resources and Environment, Hangzhou, \\ China \\ ${ }^{4}$ College of Veterinary Sciences and Animal Husbandry, Abdul Wali Khan University, Mardan, \\ Pakistan \\ ${ }^{5}$ Department of Parasitology, University of Agriculture, Faisalabad, Pakistan \\ ${ }^{6}$ Sulaiman Bin Abdullah Aba Al-Khail Centre for Interdisciplinary Research in Basic Sciences, \\ International Islamic University, Islamabad, Pakistan \\ *Corresponding author \\ e-mail: baharkk75@gmail.com; phone: +92-334-9073-552
}

(Received $5^{\text {th }}$ Dec 2018; accepted $1^{\text {st }}$ May 2019)

\begin{abstract}
Livestock plays an important role in the economy of Pakistan. Small ruminants like sheep and goats, are highly susceptible to internal parasites, particularly gastrointestinal nematodes (GINs) including Haemonchus contortus. The present study was conducted in Pakistan to test the larvicidal and ovicidal activities with different concentrations of extracts of bulbs of domestic garlic (Allium sativum) and leaves of neem tree (Azadirachta indica) against $H$. contortus. In case of larval mortality, the highest mortality was recorded as $87 \%$ at $100 \%$ extract of neem leaves, while $100 \%$ extract of garlic bulb showed $67 \%$ mortality. The highest egg hatching inhibition $(94 \%)$ was noted when neem leaves extract was used at $100 \%$ concentration, while in case of garlic extract, $100 \%$ concentration showed $80 \%$ inhibition of the eggs hatching. It was concluded that all the extracts of A. indica showed higher mortality and eggs hatching inhibition of $H$. contortus than A. sativum.
\end{abstract}

Keywords: parasites, medicinal plants, eggs hatch assay, larval mortality assay

\section{Introduction}

Agriculture always played a major role in the economy of Pakistan. In National Gross Domestic Product (GDP), agriculture contributes 24\% in which share of livestock is $12 \%$. According to the Ministry of National Food Security \& Research the estimated population of domestic sheep (Ovis aries) was 30.5 million while domestic goats (Capra aegagrus hircus) were 74.1 million during 2017-18. It is also estimated that about 40000 tons of meat from sheep and 915000 tons from goats were obtained during the year 2017-18 (Economic Survey of Pakistan 2017-2018). But this important sector of agriculture is highly susceptible to gastrointestinal nematodes (GINs). Among GINs, Haemonchus contortus, a blood-sucking nematode that belongs to the family Trichostrongylidae and class Secernentea, causing a serious disease in small ruminants called Haemonchosis (Khattak et al., 2018). 
The clinical symptoms of this disease include hemorrhagic anemia, hypo-protein anemia, and parasitic gastroenteritis in animals especially in small ruminants like sheep and goats (Mola, 2018). Haemonchus contortus infestation causes major health problems including reduction in animal productivity in terms of meat, milk and wool. The major impacts of $H$. contortus in small ruminants are associated with the blood sucking activity that results in extensive blood loss (Bowman et al., 2009). Each parasite sucks $0.05 \mathrm{ml}$ of blood per day. As a result, there is a decrease in total erythrocytes count, hemoglobin, packed cell volume, body weight, milk production and wool growth (Hepworth, 2006; Urquhart et al., 1996; Rasool et al., 1995). It is estimated that a sheep can lose $250 \mathrm{ml}$ blood/day if infected with $5000 \mathrm{H}$. contortus worms. Life cycle of this parasite takes around 21 days to complete. Its life cycle is direct i.e. no secondary host is involved in cycle completion. Every adult female parasite lays 5000-10,000 eggs per day which are then passed out in the feces (Emery et al., 2016) as shown in Figure 1.

\section{Life cycle of Haemonchus contortus}

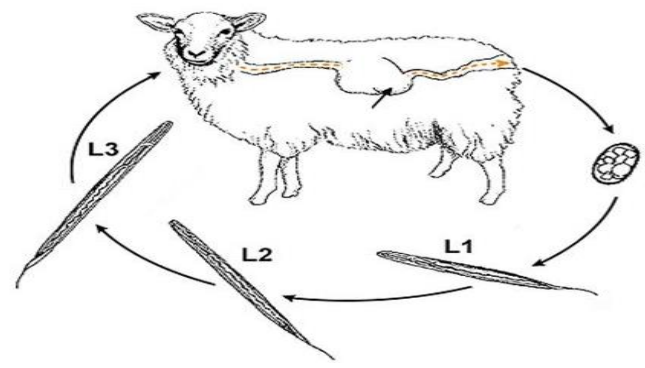

- Male and female mate, eggs get deposited into external environment

- Develop from 1 st stage larvae to infective $3^{\text {rd }}$ stage larvae

- Ingestion of $3^{\text {rd }}$ stage larvae causes cattle to become infected with Haemonchus contortus

Figure 1. Life cycle of Haemonchus contortus. (Reproduced from SlidePlayer.com)

The frequent and un-judicial use of anthelmintic drugs has led to a growing problem of parasitic resistance against the conventional therapies. Haemonchus contortus is showing resistance to the most commonly used broad spectrum anthelmintics belonging to the classes; Benzimidazoles, imidazothiazoles and Macro cyclic lactones (Kaplan, 2004; Jackson and Coop, 2000; Sangster, 1999; Miller et al., 1987).

Garlic (Allium sativum) has been reported to be a parasiticide, amoebicide, larvicide and immune-stimulant (Duke, 2002). Essential oil of these plants can also be used as alternative or supplement to the current anthelmintics therapies (Anthony et al., 2004). Neem plant, (Azadirachta indica) is known for its medicinal properties and has been used against gastrointestinal nematodes and related problems in many parts of the world (Biswas et al., 2002). Therefore, the present study was designed with the objective to evaluate the anthelmintic properties of the crude extracts of Garlic and Neem plants against $H$. contortus in small ruminants.

\section{Materials and methods}

\section{Sampling area}

Adult $H$. contortus were collected from the infected abomasums of small ruminants from slaughter houses in district Kohat of Khyber Pakhtunkhwa, Pakistan as shown in 
Figure 2. The climate in Kohat is referred to as a local steppe climate. There is little rainfall throughout the year. This location is $33^{\circ} 34^{\prime} 47.1^{\prime \prime} \mathrm{N} / 71^{\circ} 26^{\prime} 29.3^{\prime \prime} \mathrm{E}$, elevation is $395 \mathrm{~m} / 1296$ feet and barometric pressure is $97 \mathrm{KPa}$. The temperature here averages $22.8^{\circ} \mathrm{C}$. The average annual rainfall is $529 \mathrm{~mm}$.

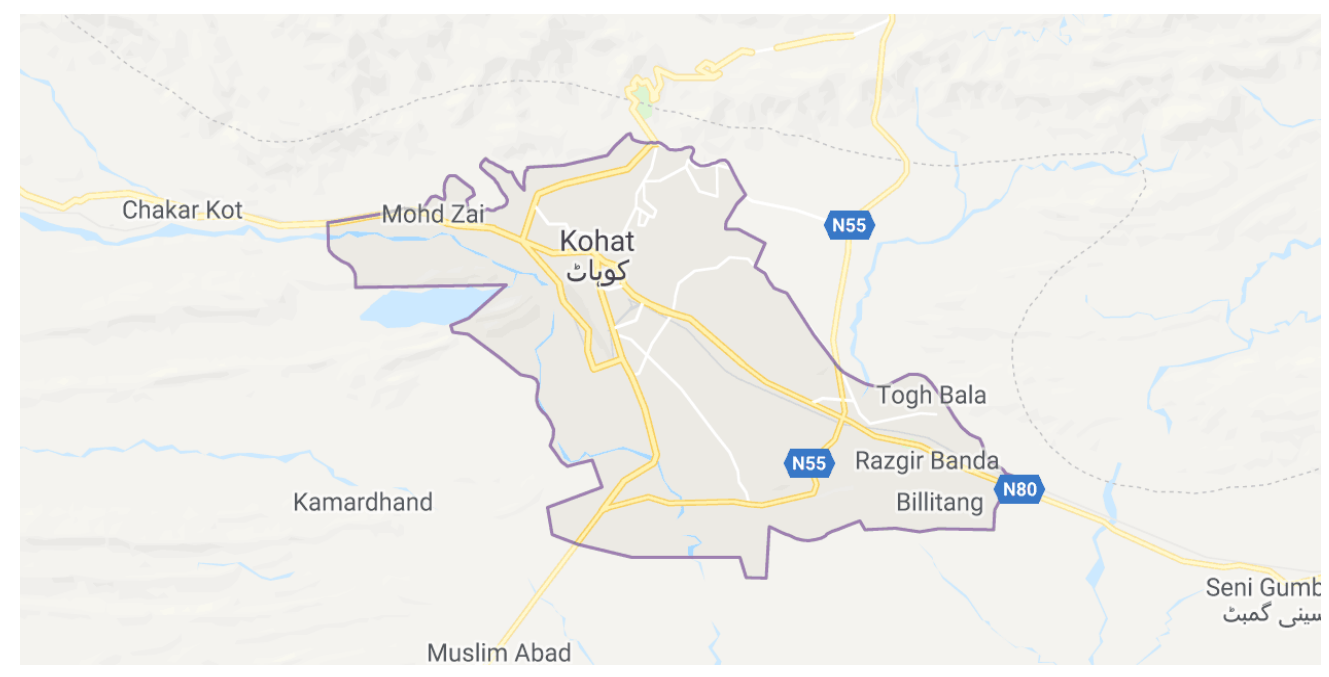

Figure 2. Sampling area of district Kohat. (Reproduced from Google Maps)

\section{Collection and isolation of $\boldsymbol{H}$. contortus}

After collection of the adult parasites, female $H$. contortus worms were separated and placed in the Petri dish containing Phosphate Buffer Saline (PBS). Petri dish containing worms were kept in incubator at $37{ }^{\circ} \mathrm{C}$. The identification of $H$. contortus was carried out on the basis of morphological features using standard keys (Urquhart et al., 1996) as shown in Figure 3.

\section{Cultivation of infective larvae}

After separation of female parasites from male parasites, eggs were recovered by grinding the female with pistol and mortar by adding $5 \mathrm{ml}$ PBS. Eggs were incubated at room temperature for $72 \mathrm{~h}$ for the development of the infective larvae (L3). After cultivation, the infective larvae (L3) were maintained in the laboratory at $25-30{ }^{\circ} \mathrm{C}$ in sterile conditions.

\section{Collection of plant materials}

Fresh and healthy plant parts of Garlic (bulbs) and Neem (leaves) (disease free) were collected from various parts of the Khyber Pakhtunkhwa, Pakistan. After collection, the plants were washed with distilled water and dried with clean clothes and then kept in the laboratory for further processing.

\section{Preparation of plant extracts}

After drying, the plant materials were cut into small pieces followed by grinding into fine powder. The powdered material was mixed with methanol in conical flask and filtered through Whattman filter paper No. 1. The filtrate was then allowed to evaporate and make them concentrated. 


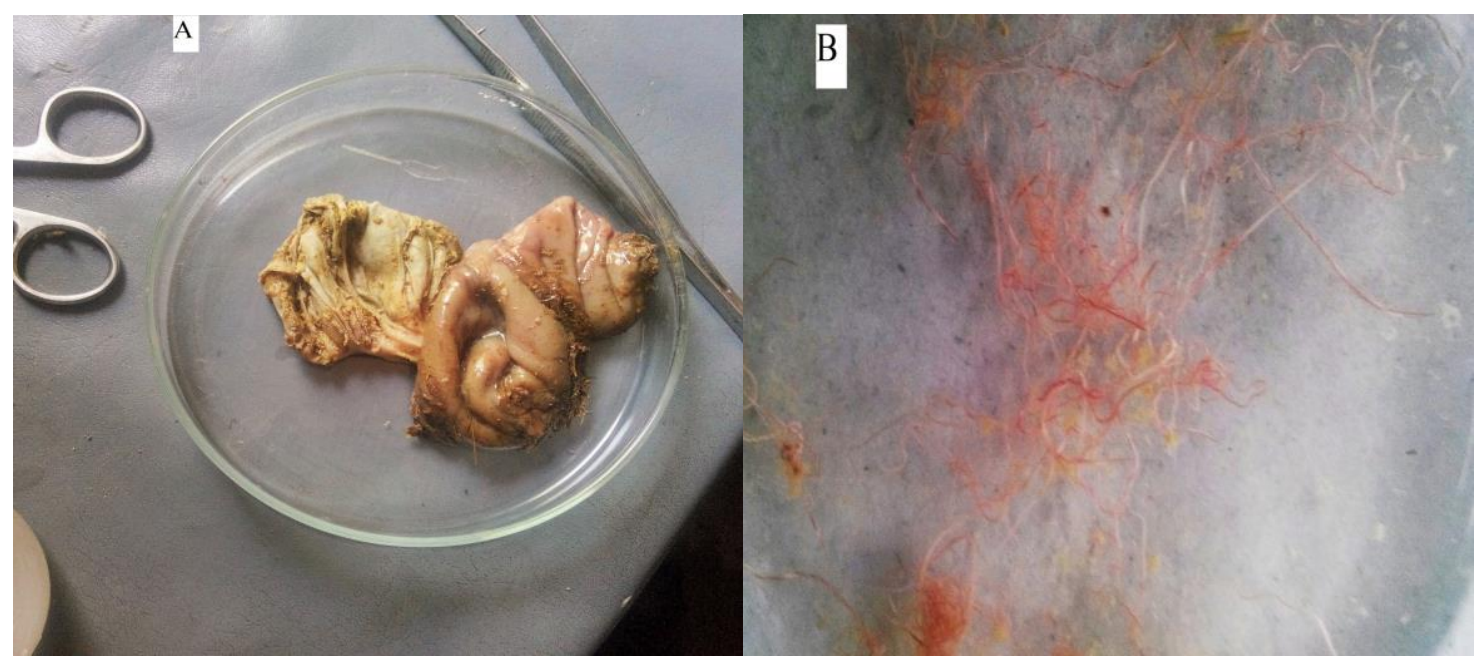

Figure 3. A Abomasum of infected sheep. B Adult worms harvested from infected abomasum

\section{Preparation of methanol extracts}

$10 \mathrm{gm}$ of the Neem and Garlic powdered materials first weighted and then dissolved in $100 \mathrm{ml}$ methanol solution in separate beakers in order to make $10 \%$ solution and mixed properly by magnetic stirrer for $15 \mathrm{~min}$. The solutions were kept on rotary shaker for $24 \mathrm{~h}$ and the mixtures were then passed through Whattman filter paper No.1 to prepare filtrate. The filtrate was taken into cork labeled bottle in sterilized condition. Different concentrations of filtrate were made i.e. $50 \%, 25 \%, 12.5 \%$ and $6.25 \%$ by adding $2.5 \mathrm{ml}$ PBS and $2.5 \mathrm{ml}$ filtrate in separate petri dishes by serial dilution method. A $100 \%(5 \mathrm{ml})$ pure extract solution was taken as a mother solution having no PBS, where PBS (5 ml) was used as a control group.

\section{Effects of plant extract on Haemonchus contortus}

Mortality of $H$. contortus was checked after $6 \mathrm{~h}$ treatment to the various concentrations of Garlic (Allium sativum) and Neem (Azadirachta indica) extracts.

\section{Statistical analysis}

Student $t$ test was used to statistically analyze the data and the significance level was kept as $P<0.05$.

\section{Results}

Mean percentage mortality of L3 stage Larvae after 6 h post-exposure of various percentages of methanol neem extracts

The selected plants of different concentration of methanol extract, Neem (100\%) was significantly effective against L3 stage larvae of Haemonchus contortus. The efficacy of methanol extracts of plants at different concentration presented in Figure 4. At $100 \%$ concentration, $87 \%$ mortality was observed. 53\%, 43\%, 37\% and $23 \%$ mortality have showed by $50 \%, 25 \%, 12.5 \%, 6.25 \%$ concentrations, respectively. In case of L3, Neem showed highest mortality as compared to Garlic extract. In positive control there was $100 \%$ mortality as shown in Figure 4. 


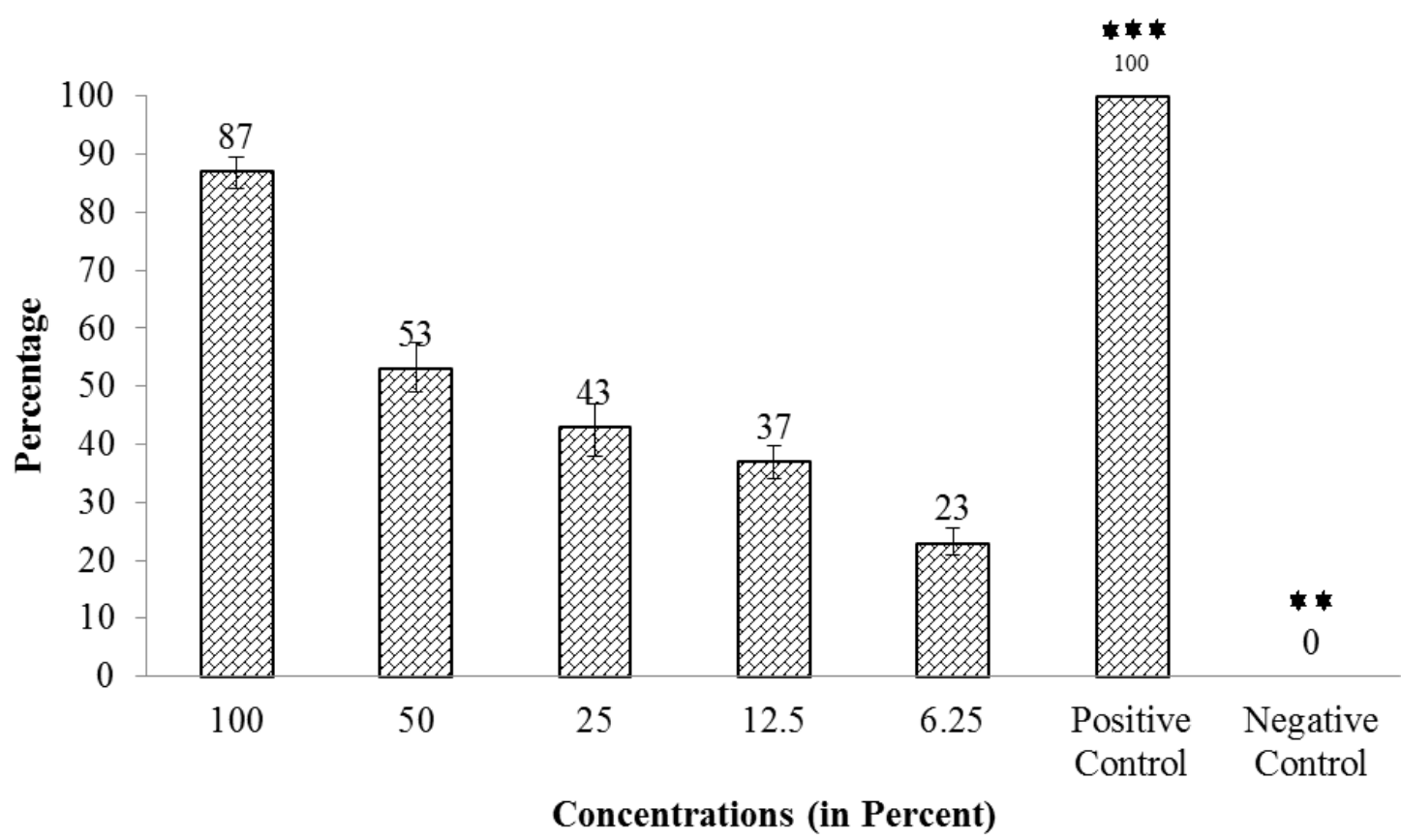

Figure 4. Mean percent mortality of L3 stage larvae after 6 h post-exposure of various concentrations of methanol neem extracts

\section{Mean percentage mortality of L3 larvae after $6 \mathrm{~h}$ post-exposure against various percentages of garlic methanol extracts}

It is evident from the data that Garlic diluted filtrate showed anthelmintics activity against L3 larvae but highest mortality has showed by $100 \%$ concentration which was noted as $67 \%$. Moreover, 50\%, 33\%, 23\% and 3\% mortalities were shown by $50 \%$, $25 \%, 12.5 \%$ and $6.25 \%$ solution, respectively. Whereas, in control group no mortality was noted as shown in Figure 5.

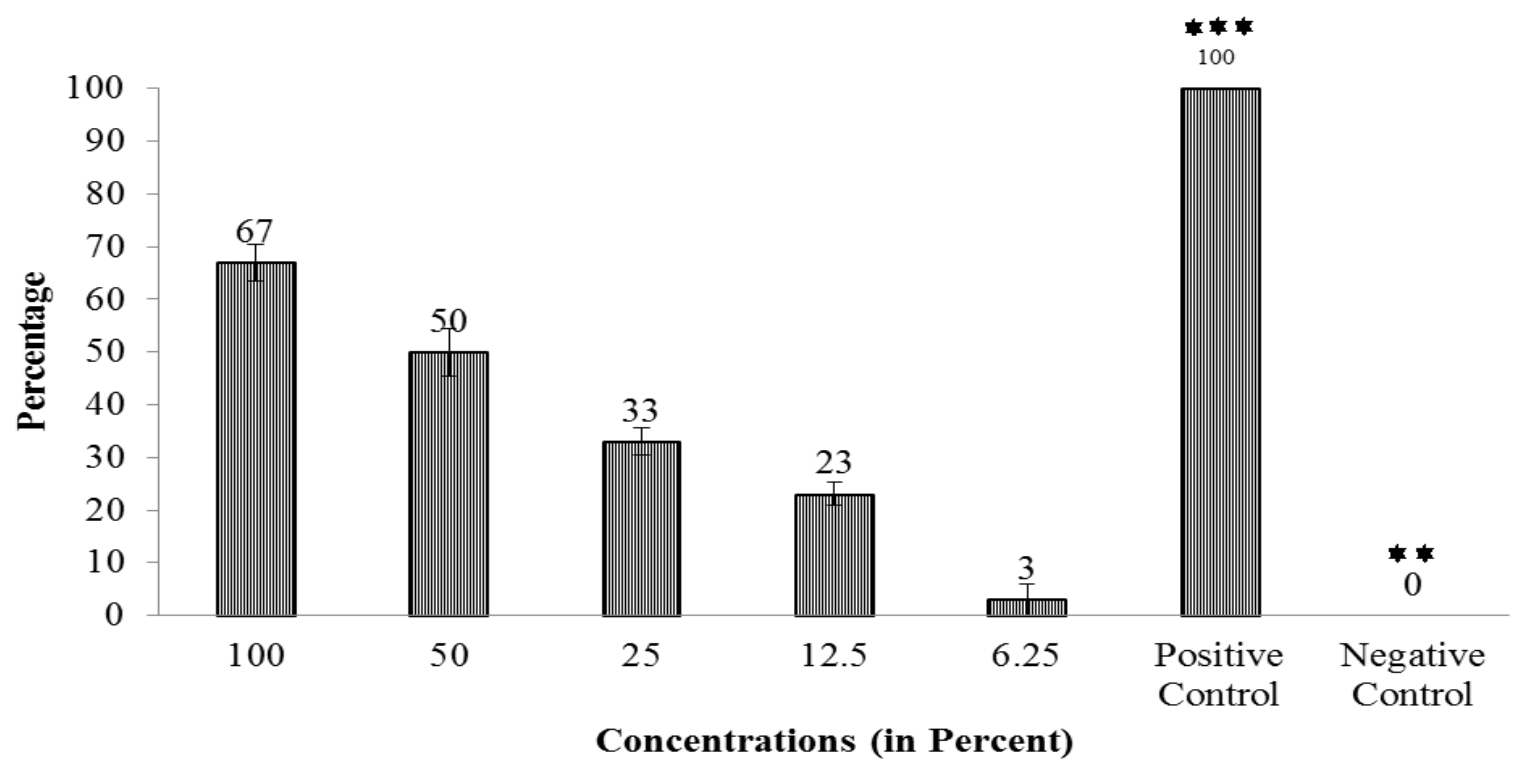

Figure 5. Mean \% mortality of larvae after treating $6 \mathrm{~h}$ with various concentration of methanolbased garlic extracts 


\section{Percent inhibition of eggs hatching of H. contortus against Neem extract}

At $100 \%$ Neem extract showed highest egg hatch inhibition which was $94 \%$ (Table 1). Second highest egg hatch inhibition was recorded for 50\% methanol extract of Neem (72\%), followed by $25 \%(54 \%)$ and $12.5 \%$ extract $(33 \%)$. The lowest inhibitions were observed for $6.25 \%$ and $3.125 \%$ that were $20 \%$ and $8 \%$, respectively.

Table 1. Percent inhibition of eggs hatching of $H$. contortus against neem extract

\begin{tabular}{c|c|c|c|c}
\hline $\begin{array}{c}\text { Concentration } \\
(\%)\end{array}$ & $\begin{array}{c}\text { No. of egg } \\
\text { inhibition in } \mathbf{1}^{\text {st }} \text { trial }\end{array}$ & $\begin{array}{c}\text { No. of egg inhibition } \\
{\text { in } \mathbf{2}^{\text {nd }} \text { trial }}^{\text {ingo. of egg inhibition }} \\
\text { in } \mathbf{3}^{\text {rd }} \text { trial }\end{array}$ & $\begin{array}{c}\text { Mean of egg } \\
\text { inhibition }^{\text {Nition }}\end{array}$ \\
\hline 100 & 94 & 96 & 92 & 94 \\
50 & 75 & 70 & 72 & 72 \\
25 & 58 & 53 & 50 & 54 \\
12.5 & 35 & 32 & 33 & 33 \\
6.25 & 20 & 18 & 21 & 20 \\
3.125 & 8 & 9 & 7 & 8 \\
Control & 0 & 0 & 0 & 0 \\
\hline
\end{tabular}

$\mathrm{P}=0.9992>0.05$, non-significant

\section{Percent inhibition of eggs hatching of $H$. contortus against garlic extract}

The $100 \%$ Garlic extract showed highest egg hatching inhibition i.e. $80 \%$ as shown in Table 2. At 50\%, 25\%, $12.5 \%, 6.25 \%$ and $3.125 \%$ egg hatching inhibition was recorded as $65 \%, 49 \%, 31 \%, 15 \%$ and $5 \%$. The results infer that concentration is directly proportional to egg hatching inhibition.

Table 2. Percent inhibition of eggs hatching of $H$. contortus against garlic extract

\begin{tabular}{c|c|c|c|c}
\hline $\begin{array}{c}\text { Concentration } \\
(\%)\end{array}$ & $\begin{array}{c}\text { No. of eggs after 3 } \\
\text { days in } \mathbf{1}^{\text {st }} \text { trial }\end{array}$ & $\begin{array}{c}\text { No. of egg inhibition } \\
\text { in 2 }^{\text {nd }} \text { trial }\end{array}$ & $\begin{array}{c}\text { No. of egg inhibition } \\
\text { in 3 } \mathbf{3}^{\text {rd }} \text { trial }\end{array}$ & $\begin{array}{c}\text { Mean of egg } \\
\text { inhibition }\end{array}$ \\
\hline 100 & 80 & 82 & 78 & 80 \\
50 & 65 & 68 & 62 & 65 \\
25 & 50 & 47 & 51 & 49 \\
12.5 & 30 & 31 & 32 & 31 \\
6.25 & 15 & 13 & 17 & 15 \\
3.125 & 5 & 5 & 6 & 5 \\
Control & 0 & 0 & 0 & 0 \\
\hline
\end{tabular}

$\mathrm{P}=01.0000>0.05$, Non-significant

\section{Discussion}

To control Haemonchus contortus, common anthelmintics are applied but not enough to erase this parasite completely as it is reported to be resistant to all three broad spectrum families of anthelmintics viz. benzimidazole, lmidazothiazole and ivermectin and against drugs with narrow spectrum of activity such as salicylanilides anthelmintics (Kaplan and Vidyashankar, 2012; Eckert, 2008). H. contortus is one of the most prevalent nematode parasites of small ruminants i.e. sheep and goats (Coles et al., 2005). Keeping in view the importance of this blood sucker, there is need of alternative 
methods other than common anthelmintics to prevent sheep and goats from this highly dangerous nematode parasite.

The present study was undertaken to check the mean percentage of egg hatching inhibition. Extract filtrate obtained from Allium sativum at different concentration showed mean of inhibited eggs of $H$. contortus in the range from $5 \%$ to $80 \%$ which is much similar when compared with work of (Hammad et al., 2012) who reported that there was a dose and time dependent antinematicidal activity of crude aqueous methanol extract (CAME) of $N$. tabacum leaves with estimated LC $_{50}$ values of 0.566 in EHA. Another study conducted in Pakistan by (Sindhu et al., 2009) showed a similar result that in egg hatching test, based on the $\mathrm{LC}_{50}$ values, most effective plants (LC50 in ppm) in their order of activity were; $N$. tabacum (0.10), S. lappa (0.73), A. indica (1.73), C. arvensis (2.51), T. chebula (5.55) and A. vasica (15.74). The allicin may have an important role in penetration of nematode egg surface, resulting in death of juveniles inside hard and protective barriers. The Azadirachtin of Azadirachta indica may have an important role in penetration of nematode egg surface, resulting in death of juveniles inside hard and protective barriers.

The third stage larvae (L3) of $H$. contortus in the present study were treated with different concentrations of the selected plants. In case of larvae, the mortality was found to be $87 \%$ at $100 \%$ methanol Azadirachta indica. Whereas, in case of Allium sativum the highest mean percent mortality was $67 \%$ at $100 \%$ extract. The methanolic diluted filtrate extract of Azadirachta indica showed approximately same result to the published paper of Rahman (2002). Rahman (2002) recorded the highest efficacy of neem leaves in alcoholic extract whereas aqueous extract has the lower efficacy (92\%) than alcoholic extract against gastrointestinal nematodiasis in goat. Sujon et al. (2008) also recorded that the efficacy of methanol extract of neem was $80 \%$ and $100 \%$ at $5 \%$ and $10 \%$ concentration, respectively. Niddhi et al. (2007), Rahman et al. (2011) and Radhakrishnan et al. (2007) also showed the efficacy of neem against Haemonchus contortus adult and L3 stage larvae.

\section{Conclusion and recommendations}

Medicinal plants traditionally used against Haemonchus contortus control showed therapeutic activity. The selected medicinal plants contain active agents especially Allicin in garlic and Azadirachtin in Neem. These plant extracts at absolute (100\%) form have the ability to lower the $H$. contortus infestation in small ruminants i.e. sheep and goats. Azadirachta indica contain potent anthelmintics compounds and therefore this plant is strongly recommended for further research studies. Mode and mechanism of action of anthelmintics plants also need to be studied in detail.

Acknowledgements. We sincerely acknowledge Pakistan Science Foundation Islamabad for providing us financial support with grant number (PSF/NSLP/KP-KUST-298). 


\section{REFERENCES}

[1] Ahmed, M., Ansari, J. A. (1989): Effect of Haemonchosis on hematology and nonspecific phosphomono esterase activities in sheep and goats. - Helminthologia 26: 295302.

[2] Anthony, J. P., Fyfe, L., Smith, H. (2005): Plant active component-a resource for antiparasitic agents. - Trends in Parasitology 21: 462-468.

[3] Biswas, K., Chattopadhyay, I., Banerjee, R. K., Bandyopadhyay, U. (2002): Biological activities and medicinal properties of Neem (Azadirachta indica). - Current Science 82: 1336-1345.

[4] Bowman, D. D. (2009): Georgis Parasitology for Veterinarians. $9^{\text {th }}$ Ed. - Saunders Elsevier, Philadelphia, PA, pp. 161-162.

[5] Coles, G. C., Rhodes, A. C., Wolstenholme, A. J. (2005): Rapid selection for ivermectin resistance in Haemonchus contortus. - Veterinary Parasitology 129: 345-347.

[6] Duke, J. A. (2002): Handbook of Medicinal Herbs. 2nd ed. - Boca Raton, FL, CRC Press.

[7] Eckert, J., Friedhoff, K. T., Zahner, H., Deplazes, P. (2008): Lehrbuch der Parasitologie für die Tiermedizin. - Enke Verlag, Stuttgart.

[8] Economic Survey of Pakistan (2017-2018): http://www.finance.gov.pk/survey_1718.html.

[9] Emery, D. L., Hunt, P. W., Le Jambre, L. F. (2016): Haemonchus contortus: the then and now, and where to from here? - International Journal for Parasitology 46(12): 755-769.

[10] Hamad, K. K., Iqbal, Z., Ud, Z., D., Sindhu, Z., Muhammad, G. (2013): Antinematicidal activity of Nicotiana tabacum L. leaf extracts to control benzimidazole-resistant Haemonchus contortus in sheep. - Pakistan Veterinary Journal 33(1): 85-90.

[11] Hepworth, K., Neary, M., Hutchens, T. (2006): Managing Internal Parasitism in Sheep and Goats. - Purdue University Cooperative Extension Service, West Lafayette, pp. 1-10.

[12] Iqbal, Z., Nadeem, Q. K., Khan, M. N., Akhtar, Waraich, F. N. (2001): In vitro anthelmintic activity of Haemonchus contortus of sheep. Allium sativum, Zingiber officinale, Curcurbi mexicana and Ficus religiosa. - International Journal of Agricultural Biology 3(4): 454-457.

[13] Jackson, F., Coop, R. L. (2000): The development of anthelmintic resistance in sheep nematodes. - Parasitology 120: 95-107.

[14] Kaplan, R. M. (2004): Drug resistance in nematodes of veterinary importance: a status report. - Trends in Parasitology 20: 477-481.

[15] Khattak, B., Safi, A. U. R., Sindhu, Z. U. D., Attaullah, M., Jamal, Q. (2018): Biological control of Haemonchus contortus by fungal antagonists in small ruminants. - Applied Ecology and Environmental Research 16(5): 5825-5835.

[16] Miller, J. E., Hembry, F. G., Kearney, M. T., Williams, J. C., Stag, L. C., Sims, D. (1987): Efficacy of levamisole and netobimin against Haemonchus contortus in lambs in Louisiana. - American Journal of Veterinary Research 48(9): 1403-1406.

[17] Mola, S. (2018): Review on control of haemonchus contortus in sheep and goat. - Journal of Veterinary Medicine and Research 5(5): 1139.

[18] Niddhi, A., Vihan, V. S., Sharma, S. D., Ashok, K. (2007): Evaluation of anthelmintic activity of Azadirachta indica (Neem) against Haemonchus contortus infection in goats. Indian Journal of Veterinary Medicine 27(2): 95-98.

[19] Radhakrishnan, L., Gomathinayagam, S., Balakrishnan, V. (2007): Evaluation of anthelmintic effect of Neem (Azadirachta indica) leaves on Haemonchus contortus in goats. - Journal of Parasitology Research 2(1): 57-62.

[20] Radostits, O. M., Gay, C. C., Hinchcliff, K. W., Constable, P. D. (2006): Veterinary Medicine: A Textbook of the Diseases of Cattle, Horses, Sheep, Pigs and Goats. Elsevier Health Sciences, Amsterdam. 
[21] Rahman, M. (2002): In vitro and in vivo anthelmintic activity of some plants against gastrointestinal nematodes of goats. - MS Thesis, Department of Parasitology, Bangladesh Agricultural University, Mymensingh.

[22] Rahman, W. A., Lee, R., Sulaiman, S. F. (2011): In vitro anthelmintic activity of Neem plant (Azadirachta indica) extract against third-stage Haemonchus contortus larvae from goats. - Global Veterinary 7(1): 22-26.

[23] Rasool, G., Iqbal, Z., Misarkhan, M., Hayat, B. (1995): Hematological disturbance associated with Haemonchosis in sheep. - Pakistan Veterinary Journal 15: 159-162.

[24] Sangster, N. C. (1999): Anthelmintic resistance: past, present, and future. - International Journal for Parasitology 29(1): 115-124.

[25] Sindhu, Z. U. D., Iqbal, Z., Asim, M., Ahmad, A., Abbas, R. Z., Aslam, B. (2014): In vitro ovicidal and wormicidal activity of six medicinal plants against Haemonchus contortus. - International Journal of Agricultural Biology 16: 1199-1203.

[26] Sujon, M. A., Mostofa M, Jahan, M. S., Das, A. R., Rob, S. (2008): Studies on medicinal plants against gastrointestinal nematodes of goats. - Bangladesh Journal of Veterinary Medicine 166(12): 373-374.

[27] Urquhart, G. M., Armout, J. Duncan, J. L., Jennings, F. W. (1996): Veterinary Parasitology. 2nd Ed. - The University of Glasgow, Scotland, pp. 228-276. 